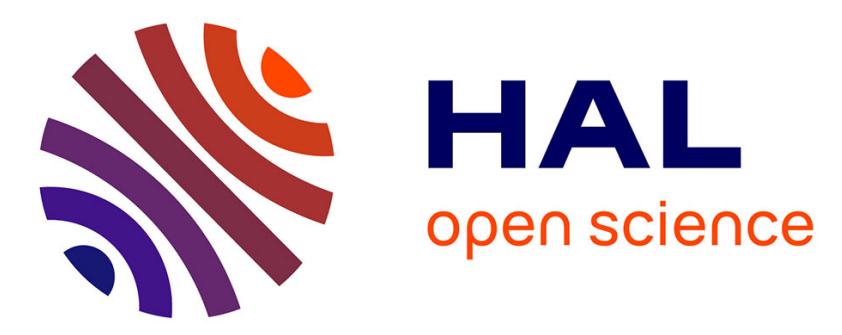

\title{
Potential of EPR spin-trapping to investigate in situ free radicals generation from skin allergens in reconstructed human epidermis: cumene hydroperoxide as proof of concept
}

Salen Kuresepi, Bertrand Vileno, Philippe Turek, Jean-Pierre Lepoittevin, Elena Giménez-Arnau

\section{To cite this version:}

Salen Kuresepi, Bertrand Vileno, Philippe Turek, Jean-Pierre Lepoittevin, Elena Giménez-Arnau. Potential of EPR spin-trapping to investigate in situ free radicals generation from skin allergens in reconstructed human epidermis: cumene hydroperoxide as proof of concept. Free Radical Research, 2018, 52 (2), pp.171-179. 10.1080/10715762.2017.1420906 . hal-02119639

\author{
HAL Id: hal-02119639 \\ https://hal.science/hal-02119639
}

Submitted on 3 May 2019

HAL is a multi-disciplinary open access archive for the deposit and dissemination of scientific research documents, whether they are published or not. The documents may come from teaching and research institutions in France or abroad, or from public or private research centers.
L'archive ouverte pluridisciplinaire HAL, est destinée au dépôt et à la diffusion de documents scientifiques de niveau recherche, publiés ou non, émanant des établissements d'enseignement et de recherche français ou étrangers, des laboratoires publics ou privés. 


\section{Potential of EPR Spin-Trapping to Investigate in situ Free Radicals Generation from Skin Allergens in Reconstructed Human Epidermis: Cumene Hydroperoxide as Proof of Concept}

Salen Kuresepi, ${ }^{a}$ Bertrand Vileno, ${ }^{\mathrm{b}}$ Philippe Turek, ${ }^{\mathrm{b}}$ Jean-Pierre Lepoittevin, ${ }^{\mathrm{a}}$ Elena Giménez-Arnau, ${ }^{\mathrm{a}, *}$

${ }^{a}$ Dermatochemistry Laboratory, University of Strasbourg-CNRS UMR 7177, Institut le Bel, 4 Rue Blaise Pascal, 67081 Strasbourg, France

${ }^{b}$ POMAM Laboratory, University of Strasbourg-CNRS UMR 7177, Institut le Bel, 4 Rue Blaise Pascal, 67081 Strasbourg, France, and French EPR Federation of Research (REseau NAtional de Rpe interDisciplinaire (RENARD, Fédération IR-RPE CNRS \#3443)

Conflicts of interest: none

Corresponding author: Elena Giménez-Arnau, Dermatochemistry Laboratory, University of Strasbourg-CNRS UMR 7177, Institut le Bel, 4 Rue Blaise Pascal, 67081 Strasbourg, France. Phone: +33368851525, E-mail: egimenez@unistra.fr 


\section{Potential of EPR Spin-Trapping to Investigate in situ Free Radicals Generation from Skin Allergens in Reconstructed Human Epidermis: Cumene Hydroperoxide as Proof of Concept}

The first step in the development of skin sensitization to a chemical, and in the elicitation of further allergic contact dermatitis, is the binding of the allergen to skin proteins after penetration into the epidermis. The so formed antigenic adduct is then recognized by the immune system as foreign to the body. Sensitizing organic hydroperoxides derived from autoxidation of natural terpenes are believed to form antigens through radical-mediated mechanisms, although this has not yet been established. So far, in vitro investigations on reactive radical intermediates derived from these skin sensitizers have been conducted in solution, yet with experimental conditions being far away from real life sensitization. In here we report for the first time, the potential use of EPR spin-trapping to study the in situ generation of free radicals derived from cumene hydroperoxide $\mathrm{CumOOH}$ in a 3D reconstructed human epidermis model RHE, thus much closer to what may happen in vivo. Among the undesirable effects associated to dermal exposure to $\mathrm{CumOOH}$, it is described to cause allergic and irritant dermatitis, being reported as a significant sensitizer. We considered exploiting usage of spin-trap DEPMPO as an extensive view of all sort of radicals deriving from $\mathrm{CumOOH}$ were observed all at once in solution. We showed that in the Episkin ${ }^{\mathrm{TM}}$ RHE model, both by incubating in the assay medium or by topical application, carbon radicals are mainly formed and this through redox reactions suggesting a key role of $\mathrm{CumOOH}$ derived carbon radicals in the antigen formation process.

Keywords: skin sensitizers, radicals, EPR spectroscopy, spin-trapping, reconstructed human epidermis 


\section{Introduction}

Allergic contact dermatitis (ACD) is the clinically relevant outcome of skin sensitization, one of the most important occupational and environmental health issues. It is a delayed-type hypersensitivity reaction, and the most frequent expression of immunotoxicity in humans [1]. Prevalence is rising worldwide, and exposure to allergens and the risk of skin sensitization have become an essential regulatory issue within industry. Thus it is nowadays crucial to predict the sensitization potential of chemicals before their marketing authorization to perform reliable risk assessment. In this context, more upstream investigations are required aiming at understanding molecular mechanisms involved in allergic-inflammatory reactions induced by sensitizers to cover all categories of molecules for risk assessment.

Chemical skin allergens (haptens) are low molecular weight compounds unable to stimulate by themselves an adaptive immune response after penetration into the epidermis. Immunogenicity is attained by their reaction with skin proteins, forming stable antigenic conjugates recognized and processed for presentation to the immune system [2]. The usual mechanism for the hapten-protein interaction is the formation of covalent bonds via two electrons mechanisms. However, some allergens do not fit this model. In this case, there is a real belief that radical-mediated mechanisms are involved in the antigen formation [3].

Many natural terpenes widely used as fragrances in consumer goods are excellent targets for autoxidation and form allylic hydroperoxides (ROOHs) on air exposure. It has been shown that these ROOHs are frequent causes of $\mathrm{ACD}$, form specific antigens and act as skin sensitizers [4]. We believe that sensitizing ROOHs form antigens via radical mechanisms starting with the cleavage of the O-O bond of weak dissociation energy $\left(175 \mathrm{~kJ} \mathrm{~mol}^{-1}\right)$. Such cleavage is an easy process allowing unstable alkoxyl $\left(\mathrm{RO}^{\circ}\right)$ /peroxyl ( $\left.\mathrm{ROO}^{\circ}\right)$ radicals to efficiently convert to longer half-life carbon centered radicals (R') via intramolecular cyclization, fragmentation and/or hydrogen abstraction. 
Our studies are focused on the identification of radical species derived from sensitizing ROOHs and on the study of their involvement in ACD for risk assessment purposes. We reported previously free radical generation from a range of ROOHs studied by EPR spin-trapping, specifically employed for the characterization of transient radicals in chemical and biological systems. Basically, the formed radical (either too short-lived or of too low concentration to be directly detected) reacts with a diamagnetic reagent (spin-trap) to form a more persistent radical (spin-adduct), whose EPR signature might be function on the trapped transient reactive species. The use of spin-traps 5-diethoxyphosphoryl-5-methyl-1-pyrroline $N$-oxide (DEPMPO) and 5,5-dimethyl-1-pyrroline $N$-oxide (DMPO) allowed the identification of different oxygen and carbon centered free radicals derived from ROOHs [5-7]. Such studies revealed that several reactive radical intermediates could issue from the ROOHs depending on their chemical structure, suggesting that different immunogenic protein chemical modifications could lead to sensitization. However, such studies were carried out in solution (aqueous buffer or semiorganic), far from mimicking real life scenario.

The aim here was to transfer the EPR spin-trapping methodology developed in solution to the potential investigation of free radicals formation issued from ROOHs in a reconstructed human epidermis (RHE) 3D model, thus much closer to what may happen in vivo. RHE consist of normal multi-layered keratinocyte cultures, being the major cell type in the epidermis and playing a key role in skin inflammatory reactions. EPR has been used for dermatological purposes and skin research mainly for the detection of free radicals in UV-irradiated skin, melanoma investigation and in vivo EPR imaging directly in skin of human volunteers [8-10], but never in the skin allergy field. In this report we describe the technology transfer by using cumene hydroperoxide $(\mathrm{CumOOH})$ as proof of concept and model for ROOHs. CumOOH is a common reference compound in EPR investigations [11-13], and it has also been reported as a significant sensitizer in guinea-pigs, with positive specific responses reported in allergy cross-reactivity studies with allergenic cyclohexene hydroperoxides [4]. 


\section{Materials and Methods}

\section{Studies in Solution}

\section{Chemicals and Reagents}

CumOOH, PBN (98\%) and DMPO were purchased from Sigma-Aldrich (Saint-Quentin Fallavier, France) and used as received. DEPMPO was synthesized as reported in the literature [14]. HEPES ( $\geq$ $99.5 \%$ ), ferrous sulfate heptahydrate $\mathrm{FeSO}_{4} .7 \mathrm{H}_{2} \mathrm{O}$ and acetonitrile $\mathrm{CH}_{3} \mathrm{CN}(99.8 \%)$ were acquired from Sigma-Aldrich (Saint-Quentin Fallavier, France). Aqueous solutions were prepared with deionized water.

\section{EPR Experiments}

EPR spectra were recorded on an EPR X-band spectrometer (EMXplus, Bruker Biospin GmbH, Germany), equipped with a high sensitivity resonator (HSW, Bruker Biospin GmbH, Germany). The $g$ calibration was performed using Bruker standard (strong pitch) with known isotropic $g$ factor of 2.0028. The principal experimental parameters values were: microwave power $4.5 \mathrm{~mW}$, modulation amplitude 0.5 to $1 \mathrm{G}$, for a resulting sweep time of ca. $120 \mathrm{~s}$ for a single scan. Up to 2 scans were accumulated to improve the signal-to-noise ratio. Spectra were recorded at room temperature $(295 \mathrm{~K} \pm 1 \mathrm{~K})$. As fast as possible after reagents mixing, the resulting sample was introduced into a glass capillary (Hirschmann, $25 \mu \mathrm{L}$ ), sealed at both ends and rapidly transferred into the EPR cavity for measurement.

\section{General Procedure in Solution}

HEPES buffer solution (10 mM, pH 6.8) was prepared by dissolving $1.19 \mathrm{~g}$ HEPES in $400 \mathrm{~mL}$ deionized water, with additional $4 \mathrm{~g} \mathrm{NaCl}$ and $0.1 \mathrm{~g} \mathrm{KCl}$. To attain $\mathrm{pH} 6.8 \mathrm{NaOH}$ pellets were added. If the $\mathrm{pH}$ went too high, it was lowered back by carefully adding $\mathrm{HCl}$ until $\mathrm{pH}$ remained stable to 6.8 . Finally, deionized water was added for a final volume of $500 \mathrm{~mL}$.

Stock solutions were prepared for $\mathrm{CumOOH}$ (5.4 mM, HEPES/CH $3 \mathrm{CN}^{9 / 1)}$, the spin-traps (100 $\mathrm{mM}$ in HEPES) and $\mathrm{FeSO}_{4} .7 \mathrm{H}_{2} \mathrm{O}(10 \mathrm{mM}$ in deionized water). $12.5 \mu \mathrm{L}$ of spin-trap solution were 
mixed with $\mathrm{FeSO}_{4} .7 \mathrm{H}_{2} \mathrm{O}$ (i. e. $0.5 \mu \mathrm{L}$ for a final concentration in the reaction mixture of $0.1 \mathrm{mM}$ ), $5 \mu \mathrm{L}$ CumOOH solution added and final volume completed to $50 \mu \mathrm{L}$. This way, final concentrations in the reaction mixture were $25 \mathrm{mM}$ spin-trap and $0.54 \mathrm{mM}$ CumOOH. The reaction mixture was subjected to stirring, further introduced into the EPR quartz capillary tube, sealed on both ends, and EPR spectra registered.

\section{Reconstructed Human Epidermis Studies}

Chemicals and Reagents

Episkin $^{\mathrm{TM}}$ (Lyon, France) is an in vitro reconstructed human epidermis (RHE) from normal human keratinocytes cultured for 13 days on a collagen matrix at the air-liquid interface. It is a $3 \mathrm{D}$ epidermis model histologically similar to human epidermis. The small $0.38 \mathrm{~cm}^{2}$ format was chosen for the studies. Immediately after arrival in the laboratory, the 3D reconstructed epidermis were removed from the agarose-nutrient solution in the shipping multiwell plate under a sterile airflow. Then, they were immediately placed in a plate in which each well was previously filled with $2 \mathrm{~mL}$ Episkin $^{\mathrm{TM}}$ maintenance or growth medium at room temperature. It was necessary to act quickly as the tissue cultures dry out rapidly when not in contact with medium. Samples were placed in the incubator at 37 ${ }^{\circ} \mathrm{C}, 5 \% \mathrm{CO}_{2}$ and saturated humidity, at least $24 \mathrm{~h}$ before incubation. Episkin ${ }^{\mathrm{TM}}$ (Lyon, France) furnished the assay medium used for incubations.

\section{EPR Experiments}

EPR spectra were recorded on an EPR X-band spectrometer (ESP300E, Bruker Biospin GmbH, Germany), equipped with a standard TE102 rectangular resonator (Bruker Biospin GmbH, Germany). The $g$ calibration was performed using Bruker standard (strong pitch) with known isotropic $g$ factor of 2.0028. The principal experimental parameters values were: microwave power of 5-10 $\mathrm{mW}$, modulation amplitude 1 to $2 \mathrm{G}$, and resulting sweep time of ca. $164 \mathrm{~s}$ to $328 \mathrm{~s}$ for a single scan. Up to 4 scans were accumulated to improve the signal-to-noise ratio. Spectra were recorded at room 
temperature $(295 \mathrm{~K} \pm 1 \mathrm{~K})$ as soon as possible after incubating the reagents. RHE were placed in an EPR tissue cell equipped with a silica window (Willmad, \#ER162TC-Q) and resulting EPR spectra recorded in situ right afterwards.

General Procedure in RHE

Incubation in the Assay Medium: CumOOH (200 $\mu \mathrm{L}$ of $5.4 \mathrm{mM} \mathrm{HEPES/CH}{ }_{3} \mathrm{CN}$ 9/1 stock solution) and DEPMPO (100 $\mu \mathrm{L}$ of $500 \mathrm{mM}$ stock solution in HEPES) were introduced in a mixture of $300 \mu \mathrm{L}$ assay medium and $1400 \mu \mathrm{L}$ of HEPES buffer. The RHE model was then placed in a well containing this mixture. After $2 \mathrm{~h}$ incubation, RHE was placed in the EPR tissue cell and EPR spectra recorded. Incubation by Topical Application to the RHE: RHE were topically treated with CumOOH in acetone $(1 \mathrm{mM}, 20 \mu \mathrm{L})$ and post incubated $\left(37^{\circ} \mathrm{C}, 5 \% \mathrm{CO}_{2}\right)$ different time periods ( 1 min to $\left.2 \mathrm{~h}\right)$. After the incubation time, the RHE were placed in the EPR tissue cell and DEPMPO (50 mM in HEPES buffer, $20 \mu \mathrm{L}$ ) was applied to the epidermis taking care to ensure that the solution was only applied to it. EPR spectra were then recorded.

\section{EPR Simulations}

All experimental EPR spectra were analyzed by means of computer simulation using labmade scripts based on Easyspin toolbox (http://www.easyspin.org) under Matlab (Mathworks) environment [15]. 


\section{Results}

\section{Studies in Solution}

Studies in solution were carried out to set up the optimal experimental conditions providing a good signal-to-noise ratio while keeping low $\mathrm{CumOOH}$ concentrations, i.e. suitable with physiological conditions. $\alpha$-Phenyl- $N$-tert-butylnitrone (PBN), DMPO and DEPMPO were used as complementary spin-traps to obtain a comprehensive picture of all radicals being formed. Spin-adducts are formed by addition of transient short-lived radicals to the $\alpha-\mathrm{C}$ of the nitronyl group of the spin-traps. PBN and DMPO are commonly used in biological media, but their low resistance to bio reductions of their spinadducts limit potential in vivo applications. DEPMPO produces spin-adducts with longer lifetime, particularly for the superoxide and alkylperoxyl radicals adducts $[16,17]$.

Radical initiation was triggered by Fe(II) induced Fenton reaction. Spin-traps, in $10 \mathrm{mM}$ buffer, were employed in an excess concentration $(25 \mathrm{mM})$ with respect to $\mathrm{CumOOH}(0.54 \mathrm{mM})$. The spintrap solution was mixed with aqueous ferrous sulfate $(0-1.7 \mathrm{mM}), \mathrm{CumOOH}$ added and the mixture subjected to conventional field-swept continuous wave-EPR spectroscopy (cw-EPR) in a glass capillary after different reaction times ( $1 \mathrm{~min}$ to $2 \mathrm{~h}$ ). Initial tests were carried out in phosphate buffer (pH 7.4) but we observed that $\mathrm{Fe}(\mathrm{II})$ concentration was a limiting factor in the generation of radical species as $\mathrm{Fe}(\mathrm{II})$-catalyzed $\mathrm{CumOOH}$ oxidation was inhibited at low Fe(II) concentrations [18] (see Supplementary Material for experimental data). The use of HEPES buffer of better stability at physiological $\mathrm{pH}$ resolved this problem: (i) similar EPR spectra were observed in HEPES solutions and (ii) $\mathrm{Fe}(\mathrm{II})$ initiation was efficient instantly at catalytic concentrations $(0.1 \mathrm{mM})$.

Relevant ${ }^{14} \mathrm{~N},{ }^{1} \mathrm{H},{ }^{31} \mathrm{P}$ hyperfine coupling constants $(h f c c s)$ of detected spin-adducts are listed in Table 1. Scheme 1 suggests mechanisms explaining 1-8 formation. (Table 1 and Scheme1 around here)

Experiments with PBN and DMPO provided an initial basis of radicals trapped while DEPMPO gave the most complete information. Very briefly, we assigned adduct $\mathbf{1}$ to a PBN-carbon centered 
radical adduct, probably the ${ }^{\circ} \mathrm{CH}_{3}$ generated by $\beta$-scission of $\mathrm{CumO}{ }^{\bullet}$ radicals [18]. Adduct 2 with $h f c c s$ also characteristic of trapped carbon radicals was observed too but at higher Fe(II) concentrations $(\geq$ $0.5 \mathrm{mM}$ ) (see Supplementary Material). In the literature, 2 has been reported only in presence of amino acids or ethanol in the reaction mixtures, which was not the case here [18-20]. A hypothetical explanation could be trapping of oxaspiro radicals in equilibrium with $\mathrm{CumO}^{\circ}$, which are suspected intermediates in known $O$-neophyl rearrangement processes [21,22]. DMPO-OCH $\mathrm{D}_{3}$ spin-adduct 3 was detected at catalytic $\mathrm{Fe}(\mathrm{II})$ levels $(0.1 \mathrm{mM})$, and ${ }^{\circ} \mathrm{CH}_{3} / \mathrm{HO}^{\circ}$ radicals also formed and trapped $(4,5)$ at higher Fe(II) concentrations [23] (see Supplementary Material).

DEPMPO was undoubtedly more valuable when compared to PBN or DMPO as a broad view of all sort of radicals deriving from $\mathrm{CumOOH}$ were observed all at once with catalytic $\mathrm{Fe}$ (II) concentration as low as $0.1 \mathrm{mM}$ (Fig. 1b). Higher Fe(II) concentrations resulted simply in ratio changes of radicals formed (Fig. 1a). We attributed the EPR spectrum shown in Fig. 1b to a mixture of spinadducts formed by trapping hydroxyl $\mathrm{HO}^{\bullet}$ (6, Fig. 1d), carbon centered (7a/7b, Fig. 1e/1f), $\mathrm{CH}_{3} \mathrm{O}^{\bullet}$ and/or possible peroxyl $\mathrm{CumOO}^{\circ}$ radicals (8, Fig. 1g) [24]. (Figure 1 around here) In the experimental spectra it is shown two low-field/high-field overlapping EPR lines that correspond to carbon centered radicals. These could be two stereoisomers $(\mathbf{7 a} / \mathbf{7 b})$ since it is known that DEPMPO can produce stereospecific adducts [25]. The same should be observed theoretically for 8-like adducts, having stereoisomers when trapping $\mathrm{CH}_{3} \mathrm{O}^{\circ}$ and/or $\mathrm{CumOO}^{\circ}$ radicals [26]. However, in our case, to differentiate between these two radicals was hardly possible as $h f c c s$ could correspond to both upon literature depending on the experimental conditions [24].

\section{Reconstructed Human Epidermis Studies}

DEPMPO was chosen for the development of the EPR spin-trapping methodology with RHE based upon (i) the results of the studies in solution where an extensive view of all sort of radicals deriving from $\mathrm{CumOOH}$ were observed all at once with catalytic $\mathrm{Fe}(\mathrm{II})$ concentration and (ii) the high 
persistency of its superoxide and alkylperoxyl radicals spin-adducts when compared to DMPO [27]. Also, DEPMPO allows a clear distinction between oxygen and carbon centered radicals [28].

Episkin $^{\mathrm{TM}}$ RHE (Lyon, France) $\left(0.38 \mathrm{~cm}^{2}\right)$ were stored at arrival in $2 \mathrm{~mL}$ provided maintenance medium (at $37^{\circ} \mathrm{C}$, in $5 \% \mathrm{CO}_{2}$ saturated humidity atmosphere). After $24 \mathrm{~h}$, the maintenance medium was replaced by $2 \mathrm{~mL}$ of assay medium.

Preliminary trials were conducted by incubating CumOOH $(0.54 \mathrm{mM})$ and DEPMPO (25 $\mathrm{mM}$ in HEPES) in the assay medium. The aim was to avoid the epidermal barrier function and check at a first sight using absorption from the bottom of RHE if CumOOH-mediated radicals could be formed within the epidermis. Even though Episkin ${ }^{\mathrm{TM}}$ RHE barrier function has been described to be less developed than that of normal skin, regarding its different lipids composition and organization, it may not be neglected [29]. For control purposes, a sample from assay medium was regularly taken (20 $\mu \mathrm{L})$ during incubation $\left(37^{\circ} \mathrm{C}, 5 \% \mathrm{CO}_{2}, 1\right.$ min to $\left.2 \mathrm{~h}\right)$, inserted into a capillary, sealed and measured by EPR at room temperature. Whatever the incubation time, no EPR signal for spin-adducts was observed in the assay medium (Fig. 2a). (Figure 2 around here) After $2 \mathrm{~h}$ incubation in the assay medium, the RHE was placed in a commercial EPR tissue cell (Willmad) equipped with a silica window and EPR spectra recorded. Although being noisy, a signal was then already observed, increasing with time (Fig. 2c-2e). Major peaks could be assigned to a carbon centered radical DEPMPO adduct (spin-adduct 7-like) based on the following set of $h f c c s a_{\mathrm{N}}=15.4 \mathrm{G}, a_{\mathrm{H}}=22.6 \mathrm{G}$ and $a_{\mathrm{P}}=48.2 \mathrm{G}$ (Fig. 2f; Table 2) and comparison with our previous data in solution (Fig. 1b). It was not possible to distinguish between isomers $7 \mathbf{a} / 7 \mathbf{b}$ due to the noise level. Control experiments without $\mathrm{CumOOH}$ were performed, i.e. after only DEPMPO incubation in the RHE and showed no EPR signal, corroborating that most probably spinadduct 7 came from trapping a carbon centered radical issued from the hydroperoxide (Fig. 2b). As shown in Fig. 2f, hydroxyl $\mathrm{HO}^{\circ}$ was also trapped in the RHE at a lower ratio. Worthy of note, after penetrating the RHE, CumOOH radical initiation should have been induced by RHE itself as no Fe(II) was included. 
Episkin $^{\mathrm{TM}}$ RHE is a very good replicate of human epidermis architecture, and is currently used for irritation and penetration tests of cosmetic and chemical compounds as replacement of in vivo testing. In recent OECD guidelines on in vitro skin irritation assessment by using such RHE system it is specified that test chemicals must be applied topically to the RHE model [30]. Also, the stratum corneum of the RHE used, and its lipid composition, must simply resist to the penetration of SDS or Triton X-100 cytotoxic benchmark chemicals. It is thus supposed that allergens can penetrate the epidermis. In consequence, with the acquired knowledge that $\mathrm{CumOOH}$ radicals can be formed within RHE as described above, and in order to get closer to real life sensitization, further experiments were based on a topical application procedure. With this purpose, RHE were treated with $\mathrm{CumOOH}$ in acetone $(1 \mathrm{mM}, 20 \mu \mathrm{L})$ on the top and incubated for different time periods $\left(37^{\circ} \mathrm{C}, 5 \% \mathrm{CO}_{2}, 1 \mathrm{~min}\right.$ to 2 h). RHE negative controls were treated only with acetone $(20 \mu \mathrm{L})$. After post incubation, RHE were placed in the EPR tissue cell, DEPMPO was then added whilst ensuring that the solution was applied to the epidermis top (50 $\mathrm{mM}$ in HEPES) and EPR spectra recorded immediately afterwards. After $5 \mathrm{~min}$ of incubation, the fingerprint of a carbon centered radical DEPMPO adduct was detected as previously observed during incubation protocol (spin-adduct 7-like), with $h f c c s a_{\mathrm{N}}=15.4 \mathrm{G}, a_{\mathrm{H}}=22.7 \mathrm{G}, a_{\mathrm{P}}=48.1 \mathrm{G}$, and yet with a better signal-to-noise ratio (Fig. 3b; Table 2). Negative controls (incubation of the sole acetone, followed by DEPMPO addition) gave no signal, indicating that the carbon radical arose from CumOOH and not by induction of radical formation on a RHE biomolecule (Fig. 3a). Best computer simulation obtained from Fig. $3 b$ is shown in Fig. $3 \mathrm{c}$ where spin-adduct 7 -like seems to be predominant. Higher incubation times resulted in a weaker signal-to-noise ratio pointing to carbon radicals formed in the epidermis shortly after hydroperoxide topical application. (Figure 3 and Table 2 around here) 


\section{Discussion}

$\mathrm{CumOOH}$ is used in the chemical industry in the manufacturing of organic peroxides, the production of phenol and acetone, and as initiator and catalyst in polymers production and fiber-reinforced plastics. It is also a strong oxidizing agent, which makes it an important intermediate in the manufacture of epoxy and polyester resin coatings. Thus, dermal exposure to $\mathrm{CumOOH}$ during manufacturing processes has been for many years of concern, and its toxicity and ability to promote skin tumor and induce epidermal hyperplasia have been described. As free radicals are considered key factors contributing to skin tumor promotion by organic peroxides, it is not surprising that $\mathrm{CumOOH}$ became an EPR reference compound regarding oxidative stress investigations. EPR spin-trapping has been used to study the production of free radicals in isolated murine keratinocytes and in murine skin treated with $\mathrm{CumOOH}$ and other organic peroxides [31,32]. Furthermore, the ability to trigger free radicals has also been suggested to be critical for the carcinogenic properties. By studying lipid extracts of mouse skin exposed to $\mathrm{CumOOH}$, it was proved the formation of in vivo lipid-derived free radicals triggered by the hydroperoxide and causing severe oxidative stress in murine skin $[33,34]$. CumOOH has also been described to cause allergic and irritant dermatitis, being reported as a significant sensitizer in guineapigs [4].

To be a sensitizer, ROOHs need to covalently bind to skin proteins to form the antigenic entity that will trigger the immunotoxic process, and this via radical processes. These start with the cleavage of the $\mathrm{O}-\mathrm{O}$ bond, allowing unstable $\mathrm{RO}^{\circ} / \mathrm{ROO}^{\circ}$ radicals formed to rearrange to longer half-life reactive carbon centered radicals $\mathrm{R}^{\circ}$. It has been argued that the hydroxyl radical $\mathrm{HO}^{\circ}$ might act as a hapten, thus affording an unspecific allergic response. However, no such unspecific responses were observed when performing cross-reactivity studies with even structurally closed related ROOHs in guinea-pigs and mice, and in clinical studies [35-37]. Most probably, specific carbon radicals $\mathrm{R}^{\circ}$ that depend on the chemical structure of the $\mathrm{ROOH}$ must be at the origin of the antigen formation. This said, the relative contribution in skin sensitization processes of $\mathrm{R}^{\cdot}$ radicals and, in parallel, of also produced radical 
oxygen species (ROS) needs still to be elucidated. In the work we report herein, the aim was to develop an EPR spin-trapping methodology using $\mathrm{CumOOH}$ as reference hydroperoxide to elucidate if radicals can be formed in 3D RHE human epidermis model directly issued from the peroxide $\left(\mathrm{RO}^{\circ} / \mathrm{ROO}^{*} / \mathrm{R}^{\circ} / \mathrm{ROS}\right)$. The objective was to clarify which radical intermediates could be involved in the antigen formation in a system closer to what may happen in in vivo sensitization.

Studies in solution were initially carried out to establish the best experimental conditions transferable to the RHE matrix (i.e. concentrations, solvent, spin-trap). Radical initiation was performed via a Fe(II) Fenton reaction and DEPMPO was taken as the optimum spin-trap when compared to $\mathrm{DMPO}$ or $\mathrm{PBN}$. Carbon centered, alkoxyl, and $\mathrm{HO}^{\bullet}$ radicals were identified. Interestingly, the developed EPR spin-trapping methodology in the Episkin ${ }^{\mathrm{TM}}$ RHE model, either by incubating in the assay medium or by topical application, indicated that carbon radicals (adducts 7-like) are mainly formed, with slight $\mathrm{HO}^{\circ}$ radical (adduct 6), suggesting again a key role of carbon radicals in the antigen formation process. Control experiments without $\mathrm{CumOOH}$ always produced no EPR signal, suggesting that DEPMPO trapped radicals most probably originate from the hydroperoxide rather than through biomolecules present in RHE. The assignment of DEPMPO-OH 6 could leave open interpretation regarding the origin of this adduct. Aside from $\mathrm{CumOOH}$, it could arise from superoxide radical adduct, the superoxide production being induced in skin cells by $\mathrm{CumOOH}$. Additional tests to decipher the $\mathrm{HO}^{\bullet}$ radical origin could be preincubation of RHE with polyethylene glycol-conjugated superoxide dismutase, a powerful free radical scavenger that acts by reducing superoxide anions. This was out of the scope of the work presented here, but will need to be addressed in a near future. It is also important to stress that in both, solution and RHE investigations, control experiments without CumOOH did not exhibit any detectable signal from Fe(II) autoxidation in HEPES or in the assay medium, perhaps because of the catalytic concentrations of Fe(II) applied.

No Fe(II) was used for radical initiation when using RHE, to mimic real life skin allergy situation. One can hypothesize that reaction of organic peroxides in the skin in the presence of one-electron 
donor agents (i.e. amino and thiol groups present in amino acids, metal complexes, enzymes) may start the electron transfer processes and further skin proteins haptenation [38-40]. Also, the potential presence in the skin of $\mathrm{Fe}(\mathrm{III})$ haem-containing enzymes might be responsible for the peroxide O-O bond cleavage and start radical processes. Reactions of model Fe(III) porphyrin complexes with oxidants, such as peroxyacids and hydroperoxides, have been extensively studied as models. The cleavage has been confirmed but a clear mechanistic consensus has not evolved on the homolytic or heterolytic nature of the $\mathrm{O}-\mathrm{O}$ bond cleavage by these species, both kinds of mechanisms being possible [41-44].

\section{Conclusion}

To our knowledge, EPR spectroscopy had never been used before for the study of radicals derived from skin allergenic substances in RHE. In this study, EPR spin-trapping allowed us for the first time to monitor the formation of carbon radicals issued from $\mathrm{CumOOH}$ in a 3D epidermis model. This is an important achievement opening new perspectives and mechanistic insights for the molecular understanding of sensitization processes to precursors of radical intermediates (i.e. allylic hydroperoxides derived from autoxidation of natural terpenes, aromatic phenols, aromatic amines).

Since the 1980s, RHE models have been developed successfully as alternative methods to animal experiments to assess skin penetration of chemicals, and for predicting epidermal responses to irritants and sensitizers. The development and use of EPR methodologies to follow radical production and stress induction of allergens in RHE models described in this work could be further used as an alternative method and an ex vivo indication of induced free radical processes occurring in skin and would be valuable afterwards to study other dermato-oxidation events. These novel studies on the reactivity understanding through radical mechanisms, and the influence on the epidermis cell environment, should help for the development of specific alternative methods for skin sensitization assessment adapted to sensitizers reacting through radical mechanisms. 


\section{Acknowledgements}

This research was supported by the International Center for Frontier Research in Chemistry (icFRC, Strasbourg, France, grant number JLE-FRC-0001). The authors thank the French Ministry of Research, the University of Strasbourg, the CNRS and the REseau NAtional de Rpe interDisciplinaire (RENARD, Fédération IR-RPE CNRS \#3443). 


\section{References}

[1] Pesonen M, Jolanki R, Larese Filon F, Wilkinson M, Kręcisz B, Kieć-Swierczyńska M, et al. Patch test results of the European baseline series among patients with occupational contact dermatitis across Europe - analyses of the European Surveillance System on Contact Allergy network, 20022010. Contact Dermatitis 2015; 72: 154-163.

[2] Lepoittevin JP. Molecular aspects in allergic and irritant contact dermatitis. In Johansen JD, Frosch PJ, Lepoittevin JP (Eds.) Contact Dermatitis $5^{\text {th }}$ Ed. Springer-Verlag, Berlin, Heidelberg, 2011, pp. 91-110.

[3] Karlberg AT, Bergström MA, Börje A, Luthman K, Nilson JL. Allergic contact dermatitisformation, structural requirements, and reactivity of skin sensitizers. Chem. Res. Toxicol. 2008; 21: 53-69.

[4] Bråred Christensson J, Matura M, Bäcktorp C, Börje A, Nilsson JL, Karlberg AT. Hydroperoxides form specific antigens in contact allergy. Contact Dermatitis 2006; 55: 230-237.

[5] Giménez-Arnau E, Haberkorn L, Grossi L, Lepoittevin JP. Identification of radical species derived from allergenic 15-hydroperoxyabietic acid and insights into the behaviour of cyclic tertiary allylic hydroperoxides in Fe(II)/Fe(III) systems. Tetrahedron 2008; 64: 5680-5691.

[6] Kao D, Chaintreau A, Lepoittevin JP, Giménez-Arnau E. Synthesis of allylic hydroperoxides and EPR spin-trapping studies on the formation of radicals in iron systems as potential initiators of the sensitizing pathway. J. Org. Chem. 2011; 76: 6188-6200.

[7] Johansson S, Giménez-Arnau E, Grotli M, Karlberg AT, Börje A. Carbon- and oxygen-centered radicals are equally important haptens of allylic hydroperoxides in allergic contact dermatitis. Chem. Res. Toxicol. 2008; 21: 1536-1547.

[8] He G, Samouilov A, Kuppusamy P, Zweier JL. In vivo EPR imaging of the distribution and metabolism of nitroxide radicals in human skin. J. Magn. Res. 2001; 148: 155-164. 
[9] Jurkiewicz BA, Buettner GR. EPR detection of free radicals in UV-irradiated skin: mouse versus human. Photochem. Photobiol. 1996; 64: 918-922.

[10] Plonka PM. Electron paramagnetic resonance as a unique tool for skin and hair research. Exp. Dermatol. 2009; 18: 472-484.

[11] Davies MJ, Slater TF. Studies on the photolytic breakdown of hydroperoxides and peroxidized fatty acids by using electron spin resonance spectroscopy. Spin trapping of alkoxyl and peroxyl radicals in organic solvents. Biochem. J. 1986; 240: 789-795.

[12] Ueda J, Saito N, Ozawa T. ESR spin trapping studies on the reactions of hydroperoxides with Cu (II) complex. J. Inorg. Biochem. 1996; 64: 197-206.

[13] Taffe BG, Takahashi N, Kensler TW, Mason RP. Generation of free radicals from organic hydroperoxide tumor promoters in isolated mouse keratinocytes. J. Biol. Chem. 1987; 262: 12143-12149.

[14] Barbati S, Clément JL, Olive G, Roubaud V, Tuccio B, Tordo P. In Minisci F. Ed. Free Radicals in Biology and Environment. Kluwer Academic Publishers, Dordrecht, The Netherlands, 1997, pp. 39-47.

[15] Stoll S, Schweiger A. EasySpin, a comprehensive software package for spectral simulation and analysis in EPR. J. Magn. Res. 2006; 178: 42-55

[16] Clement JL, Gilbert BC, Ho WF, Jackson ND, Newton MS, Silvester S, Timmins GS, Tordo P, Whitwood AC. Use of a phosphorylated spin trap to discriminate between the hydroxyl radical and other oxidising species. J. Chem. Soc. Perkin Trans. 2. 1998: 1715-1718.

[17] Liu KJ, Miyake M, Panz T, Swartz H. Evaluation of DEPMPO as a spin trapping agent in biological systems. Free Rad. Biol. Med. 1999; 26: 714-721. 
[18] Pazos M, Andersen ML, Skibsted LH. Amino acid and protein scavenging of radicals generated by iron/hydroperoxide system: an electron spin resonance spin trapping study. J. Agric. Food Chem. 2006; 54: 10215-10221.

[19] Davies MJ, Fu S, Dean RT. Protein hydroperoxides can give raise to reactive free radicals. Biochem. J. 1995; 305: 643-649.

[20] Augusto O, Montellano PRO, Quintanilha A. Spin-trapping of free radicals formed during microsomal metabolism of ethylhydrazine and acetylhydrazine. Biochem. Biophys. Res. Commun. 1981; 101: 1324-1330.

[21] Salomone M, Bietti M, Calcagni A, Gente G. Phenyl bridging in ring-substituted cumyloxyl radicals. A product and time-resolved kinetic study. Org. Lett. 2009; 11: 2453-2456.

[22] DiLabio GA, Ingold KU, Lin S, Litwinienko G, Mozenson O, Mulder P, Tidwell TT. Isomerization of triphenylmethoxyl: the Wieland free-radical rearrangement revisited a century later. Angew. Chem. Int. Ed. 2010; 49: 5982-5985.

[23] Guo Q, Qian SY, Mason RP. Separation and identification of DMPO adducts of oxygencentered radicals formed from organic hydroperoxides by HPLC-ESR, ESI-MS and MS/MS. J. Am. Soc. Mass Spectrom. 2003; 14: 862-871.

[24] Karoui H, Chalier F, Finet JP, Tordo P. DEPMPO: an efficient tool for the coupled ESR-spin trapping of alkylperoxyl radicals in water. Org. Biomol. Chem. 2011; 9: 2473-2480.

[25] Clément JL, Finet JP, Fréjaville C, Tordo P. Deuterated analogues of the free radical trap DEPMPO: synthesis and EPR studies. Org. Biomol. Chem. 2003; 1: 1591-1597.

[26] Dikalov S, Tordo P, Mooten A, Mason RP. Characterization of the high resolution ESR spectra of the methoxyl radical adducts of 5-(diethoxyphosphoryl)-5-methyl-1-pyrroline $N$-oxide (DEPMPO). Free Rad. Res. 2003; 37: 705-712. 
[27] Frejaville C, Karoui H, Tuccio B, Le Moigne F, Culcasi M, Pietri S, Lauricella R, Tordo P. 5(Diethoxyphosphoryl)-5-methyl-1-pyrroline $N$-oxide: a new efficient phosphorylated nitrone for the in vitro spin trapping of oxygen-centered radicals. J. Med. Chem. 1995; 38: 258-265.

[28] Stolze K, Udilova N, Nohl H. Spin trapping of lipid radicals with DEPMPO-derived spin traps: detection of superoxide, alkyl and alkoxyl radicals in aqueous and lipid phase. Free Rad. Biol. Med. 2000; 29: 1005-1014.

[29] Ponec M, Boelsma E, Gibbs S, Mommaas M. Characterization of reconstructed skin models. Skin Pharmacol. Appl. Skin Physiol. 2002; 15 (Suppl. 1): 4-17.

[30] OECD testing guideline 439, 2015. In vitro skin irritation: RHE test method. DOI: 10.1787/9789264242845-en.

[31] Timmins GS, Davies MJ. Free radical formation in murine skin treated with tumour promoting organic peroxides. Carcinogenesis 1993; 14: 1499-1503.

[32] Timmins GS, Davies MJ. Free radical formation in isolated murine keratinocytes treated with organic peroxides and its modulation by antioxidants. Carcinogenesis 1993; 14: 1615-1620.

[33] Shvedova AA, Kisin ER, Murray AR, Kommineni C, Castranova V, Mason RP, Kadiiska MB, Gunther MR. Antioxidant balance and free radical generation in vitamin E-deficient mice after dermal exposure to cumene hydroperoxide. Chem. Res. Toxicol. 2002; 15: 1451-1459.

[34] Shvedova AA, Kisin ER, Murray AR, Kommineni C, Vallyathan V, Castranova V. Pro/antioxidant status in murine skin following topical exposure to cumene hydroperoxide throughout the ontogeny of skin cancer. Biochemistry (Moscow) 2004; 69: 23-31.

[35] Bråred-Christensson J, Matura M, Backtorp C, Börje A, Nilsson JLG, Karlberg AT. Hydroperoxides form specific allergens in contact allergy. Contact Dermatitis 2006; 55: 230237. 
[36] Bråred-Christensson J, Johansson S, Hagvall L, Jonsson C, Börje A, Karlberg AT. Limonene hydroperoxide analogues differ in allergenic activity. Contact Dermatitis 2008; 59: 344-352.

[37] Deza G, García-Bravo B, Silvestre JF, Pastor MA, González-Pérez R, Heras-Mendaza F, Mercadre P, Fernández-Redondo V, Niklasson B. Giménez-Arnau A, GEIDAC. Contact sensitization to limonene and linalool hydroperoxides in Spain: a GEIDAC prospective study. Contact Dermatitis 2017; 76: 74-80.

[38] Moriarty-Craige SE, Jones DP. Extracellular thiols and thiol/disulphide redox in metabolism. Annu. Rev. Nutr. 2004; 24: 481-509.

[39] Fujimoto A, Masuda T. Chemical interaction between polyphenols and a cysteinyl thiol under radical oxidation controls. J. Agric. Food Chem. 2012; 60: 5142-5151.

[40] Grossi L. The mechanism of oxidation of aniline by peroxy-compounds: can EPR spectroscopy help to discriminate between one-electron transfer and a nucleophilic substitution process? Res. Chem. Intermed. 1993; 19: 697-705.

[41] Traylor TJ, Kim C, Fann WP, Perrin CL. Reactions of hydroperoxides with iron (III) porphyrins: heterolytic cleavage followed by hydroperoxide oxidation. Tetrahedron 1998; 54: 7977-7986.

[42] Traylor TG, Tsuchiya S, Byun YS, Kim C. High-yield epoxidations with hydrogen peroxide and tert-butyl hydroperoxide catalyzed by iron(III) porphyrins: heterolytic cleavage of hydroperoxides. J. Am. Chem. Soc. 1993; 114: 2775-2781.

[43] Almarsson O, Bruice TC. A Homolytic mechanism of O-O bond scission prevails in the reactions of alkyl hydroperoxides with an octacationic tetraphenylporphinato-iron(III) complex in aqueous solution. J. Am. Chem. Soc. 1995; 117: 4533-4544. 
[44] Labeque R, Marnett LJ. Homolytic and heterolytic scission of organic hydroperoxides by (meso-tetraphenylporphinato)iron(III) and its relation to olefin epoxidation. J. Am. Chem. Soc. 1989; 111: 6621-6627. 
Table 1

Table 1. Coupling constants of spin-adducts identified in solution studies

\begin{tabular}{|c|c|c|c|c|c|}
\hline \multirow[t]{2}{*}{ Spin-trap } & \multicolumn{4}{|c|}{ Coupling constants } & \multirow[t]{2}{*}{ Assignment } \\
\hline & $a_{\mathrm{N}}(\mathrm{G})$ & $a_{\mathrm{H}}(\mathrm{G})$ & $a_{\mathrm{P}}(\mathrm{G})$ & $g$ & \\
\hline PBN & 15.3 & 3.5 & & 2.0060 & 1 PBN-carbon R [18]* \\
\hline PBN & 16.6 & 3.6 & & 2.0059 & 2 PBN-carbon R $[18,19,20]^{*}$ \\
\hline DMPO & 14.6 & $10.8(1.4)$ & & 2.0055 & 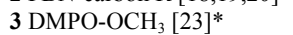 \\
\hline DMPO & 16.4 & 23.7 & & 2.0053 & 4 DMPO-carbon R [23]* \\
\hline DMPO & 15.3 & 15.0 & & 2.0057 & 5 DMPO-OH [23]* \\
\hline DEPMPO & 14.1 & 13.4 & 47.5 & 2.0059 & 6 DEPMPO-OH [24] \\
\hline DEPMPO & 15.3 & 22.6 & 47.9 & 2.0057 & 7a DEPMPO-carbon R [24] \\
\hline DEPMPO & 15.3 & 19.9 & 45.8 & 2.0059 & 7b DEPMPO-carbon R [24] \\
\hline DEPMPO & 13.1 & 9.4 & 48.0 & 2.0059 & $\begin{array}{c}8 \text { DEPMPO-OCH } \\
\text { DEPAd/or } \\
\text { DEPPO-OOCum [24] }\end{array}$ \\
\hline
\end{tabular}

* See Supplementary Material for experimental data. 
Table 2

Table 2. Spin-adducts formed from CumOOH/DEPMPO system in RHE [24,28]

\begin{tabular}{cccc}
\hline $\begin{array}{c}\text { Incubation in assay medium } \\
\text { assignment, } g, h f c c s(\mathrm{G})\end{array}$ & \multicolumn{2}{c}{$\begin{array}{c}\text { Topical application } \\
\text { assignment, } g, h f c c s(\mathrm{G})\end{array}$} \\
\hline $\mathbf{6}(28 \%)$ & $\mathbf{7}(72 \%)$ & $\begin{array}{c}\mathbf{6}(7 \%) \\
\text { DEPMPO-OH }\end{array}$ & $\begin{array}{c}\mathbf{7}(93 \%) \\
\text { DEPMPO-carbon R }\end{array}$ \\
DEPMPO-OH & DEPMPO-carbon R & & $g=2.0052$ \\
$g=2.0055$ & $g=2.0050$ & $g=2.0050$ & $a_{\mathrm{N}}=15.4$ \\
$a_{\mathrm{N}}=14.6$ & $a_{\mathrm{N}}=15.4$ & $a_{\mathrm{N}}=15.0$ & $a_{\mathrm{H}}=22.7$ \\
$a_{\mathrm{H}}=13.2$ & $a_{\mathrm{H}}=22.6$ & $a_{\mathrm{H}}=13.4$ & $a_{\mathrm{P}}=48.1$ \\
$a_{\mathrm{P}}=46.2$ & $a_{\mathrm{P}}=48.2$ & $a_{\mathrm{P}}=44.8$ & \\
\hline
\end{tabular}


Scheme 1

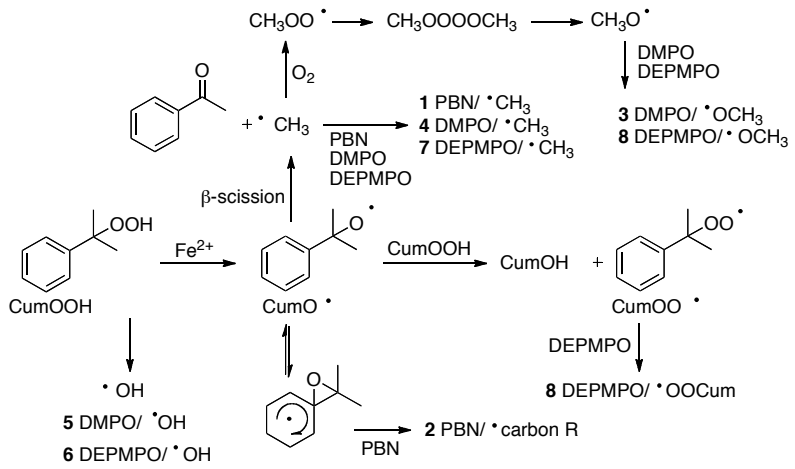


Figure 1
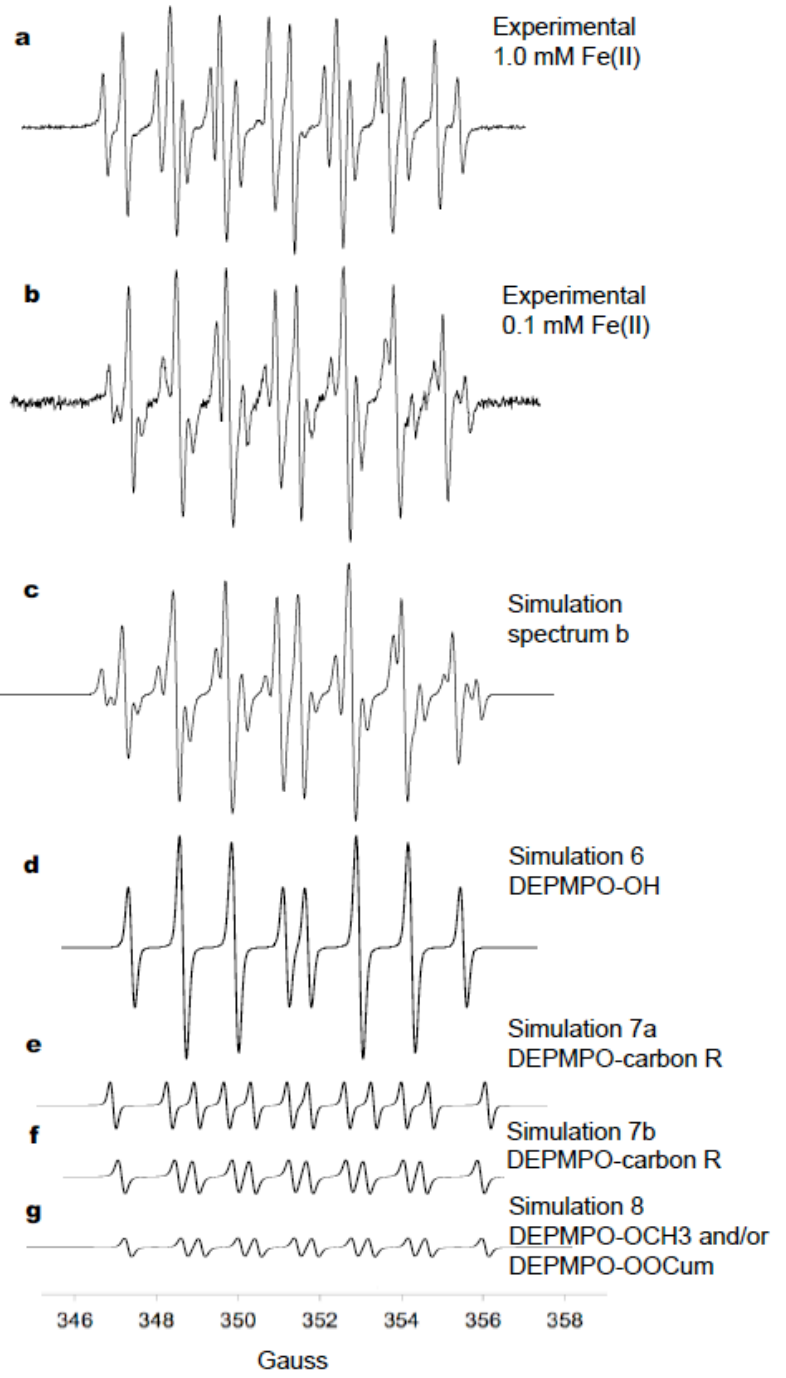
Figure 2

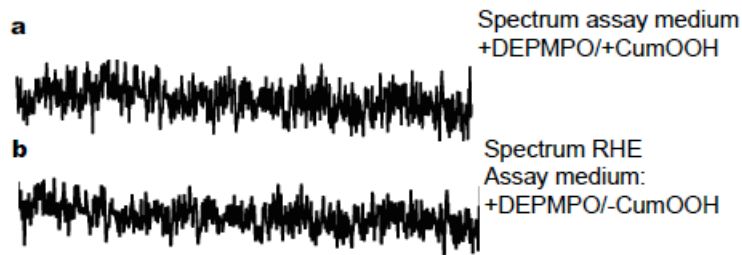

c

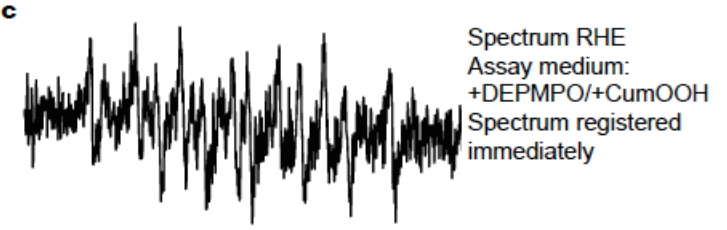

d

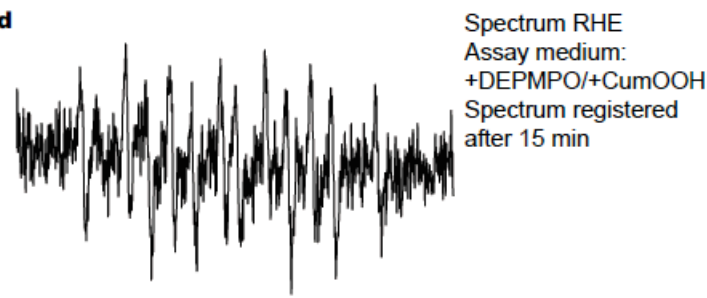

Spectrum RHE

e $|+|$ Assay medium:
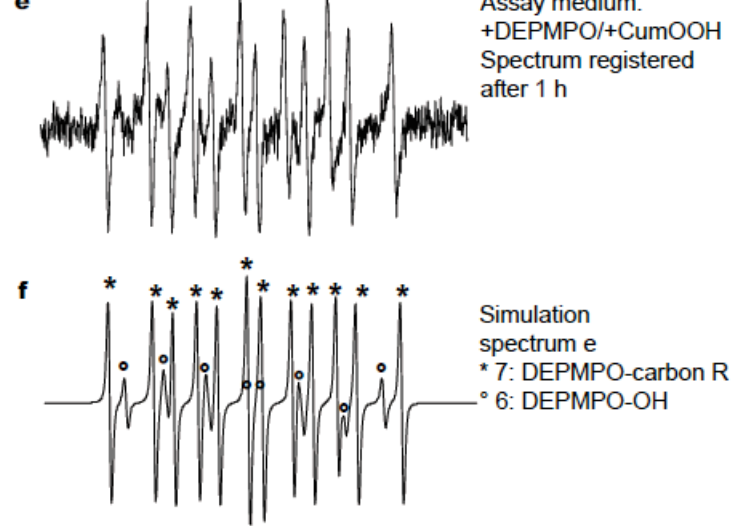

$\begin{array}{llllllll}3360 & 3380 & 3400 & 3420 & 3440 & 3460 & 3480 & 3500\end{array}$

Gauss 
Figure 3

a

Spectrum RHE

Topical application

+acetone/+DEPMPO
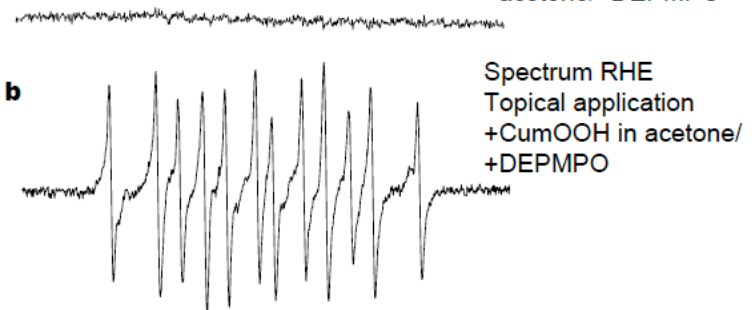

c

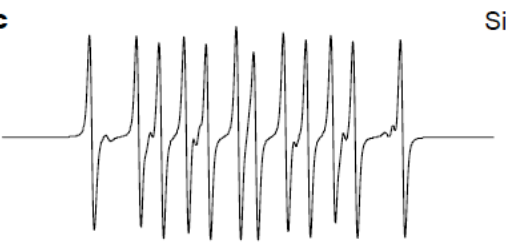

Simulation

d

Simulation 7

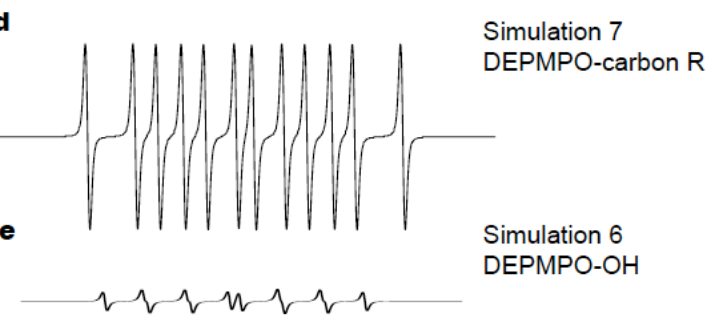

$\begin{array}{llllllll}3360 & 3380 & 3400 & 3420 & 3440 & 3460 & 3480 & 3500\end{array}$

Gauss 


\section{Legends}

Scheme 1. Formation of $\mathrm{CumOOH} / \mathrm{Fe}(\mathrm{II})$ spin-adducts 1-8 and related mechanisms. Fe(II) radical initiation produce $\mathrm{CumO}^{\circ}$ radicals. Carbon centered radicals can be formed from initial $\mathrm{CumO}{ }^{\bullet}$ by $\beta$ scission or by its equilibrium with oxaspiro radicals. From further diverse rearrangements, methoxy $\mathrm{CH}_{3} \mathrm{O}^{\circ}$ and peroxyl $\mathrm{CumOO}^{\circ}$ radicals are also formed.

Figure 1. EPR spectra obtained with CumOOH $(0.54 \mathrm{mM})$ and DEPMPO $(25 \mathrm{mM})$ dissolved in HEPES (10 mM, pH 6.8) in presence of Fe(II) registered immediately after mixing (a) with $1 \mathrm{mM}$ $\mathrm{Fe}(\mathrm{II})$; (b) with $0.1 \mathrm{mM} \mathrm{Fe(II);} \mathrm{(c)} \mathrm{computer} \mathrm{simulation} \mathrm{of} \mathrm{spectrum} \mathrm{(b);} \mathrm{(d-g)} \mathrm{deconvolution} \mathrm{of}$ spectrum (c) with $6(56.5 \%), 7 \mathrm{a}(16.5 \%), 7 \mathrm{~b}(16 \%)$ and $8(11 \%)$.

Figure 2. Preliminary trials incubating CumOOH (0.54 mM) and DEPMPO (25 mM in HEPES) in the assay medium: (a) sample from the assay medium after $2 \mathrm{~h}$ incubation with DEPMPO and CumOOH; (b) spectrum of RHE when the assay medium is incubated $2 \mathrm{~h}$ with single DEPMPO; (c) spectrum of RHE when the assay medium is incubated with DEPMPO and $\mathrm{CumOOH}$, registered immediately; (d) registered after $15 \mathrm{~min}$; (e) registered after $1 \mathrm{~h}$; (f) computer simulation of spectrum (e) with labels identifying each radical formed (* 7-like DEPMPO-carbon R (72\%) and ${ }^{\circ}$ DEPMPO-OH (28\%)).

Figure 3. EPR spectra obtained in RHE topical application experiments by using CumOOH (1 mM in acetone) and DEPMPO (50 mM in HEPES): (a) RHE control experiment with single DEPMPO and vehicle; (b) RHE spectra after $\mathrm{CumOOH}$ application and incubation $\left(5 \mathrm{~min}, 37^{\circ} \mathrm{C}, 5 \% \mathrm{CO}_{2}\right)$ followed by DEPMPO addition; (c) computer simulation of spectrum (b); (d-e) deconvolution of 7 (93\%) and 6 (7\%). 